Int. J. Electrochem. Sci., 15 (2020) 9245 - 9255

International Journal of

ELECTROCHEMICAL

SCIENCE

www.electrochemsci.org

\title{
Electrochromic and Electrofluorochromic Performance of Novel Polysiloxane bearing Tetraaniline and Fluorescein Groups
}

\author{
Yang Yimeng, Chao Danming* \\ College of Chemistry, Jilin University, Changchun, 130012, P.R. China. \\ *E-mail: chaodanming@jlu.edu.cn
}

doi: $10.20964 / 2020.09 .40$

Received: 3 May 2020 / Accepted: 28 June 2020 / Published: 10 August 2020

Color and fluorescence dual-switching materials have recently attracted considerable attention of researchers, primarily because of their unique features in practical applications such as smart sensors, intelligent displays, multipurpose optical devices, and so on. Herein, a novel networked polysiloxane bearing tetraaniline and fluorescein groups (PSTF) was designed and synthesized via electrochemistryassisted hydrolytic crosslinking reaction. The obtained porous interpenetrating PSTF film revealed expected electrochromic properties with clear color change, quick switching response, and acceptable coloration efficiency. By virtue of energy transfer between electroactive tetraaniline and photoluminescent fluorescein, PSTF film exhibited obvious fluorescent switching behavior under the applied potentials. Furthermore, the fluorescence switching upon acid/base substance was also revealed and investigated, ascribed to the variable molecular structure of PSTF.

Keywords: electrochromic; electrofluorochromic; polysiloxane; oligoaniline

\section{FULL TEXT}

(C) 2020 The Authors. Published by ESG (www.electrochemsci.org). This article is an open access article distributed under the terms and conditions of the Creative Commons Attribution license (http://creativecommons.org/licenses/by/4.0/). 